\title{
Synoptic Analysis Clarifies Childhood Leukemia Risk from ELF Magnetic Field Exposure
}

\author{
Norbert Leitgeb \\ Institute of Health Care Engineering, Graz University of Technology, Graz, Austria \\ Email: norbert.leitgeb@tugraz.at
}

Received 28 August 2015; accepted 19 October 2015; published 22 October 2015

Copyright (C) 2015 by author and Scientific Research Publishing Inc.

This work is licensed under the Creative Commons Attribution International License (CC BY). http://creativecommons.org/licenses/by/4.0/

(c) (i) Open Access

\begin{abstract}
In spite of 36 years epidemiologic research, there is still an ongoing controversy about a causal link between childhood leukemia (CL) and exposure to extremely low frequency (ELF) magnetic fields (MF). Public concern has been increased by the fact that ELF MF have been classified as possibly carcinogenic to humans (class 2B) while exposure limits still remain three orders of magnitudes above reported CL risk onset levels. In a new synoptic approach rather than few selected ORs, all reported epidemiological risk estimates (ORs) are analyzed, both pooled together as well as separated into sub-pools of different exposure metric as well as of high and low exposure levels. The results explain the worrying offset of ORs towards increased CL risk as well as the reported puzzling dose-response at low MF levels as an artifact caused by the small-number effect. The synoptic analysis clarifies that ORs critically depend on statistical power. With increasing statistical power ORs decrease and finally converge to and stay at zero risk. This is found consistently at the entire data pool as well as at all sub-pools related to investigated exposure parameters (wire code, distance to MF source, and magnetic field value). Former contradictory results can now be explained. The synoptic analysis provides convincing evidence that the risk of childhood leukemia is not increased by exposure to ELF magnetic fields. IARC's classification of ELF MF needs revision.
\end{abstract}

\section{Keywords}

Health Risk, Long-Term Effect, Carcinogenicity, Magnetic Field, Power Line

\section{Introduction}

Since 1979 when the first epidemiologic study has reported on an increased prevalence of childhood leukemia 
(CL) in the presence of extremely low frequency (ELF) magnetic fields (MF) [1], in spite of many subsequent epidemiologic studies of the following 36 years the debate about a causal relationship is still ongoing. Based on merely epidemiologic evidence on a possible association with childhood leukemia (but not with other cancers neither in adults nor in children), the International Agency for Research on Cancer (IARC) of the World Health Organization (WHO) has classified ELF MF as possibly carcinogenic to humans, class 2B [2]. Based on reported risk estimates, the impact of an increased CL risk has been theoretically quantified to be about $1.5 \%$ - $2 \%$ of all incident childhood leukemia cases with annually 50 - 60 additional cases in the whole European Union (Croatia excluded) [3].

Health concern is based in particular on the puzzling fact that reported CL risk estimates (ORs) exhibit an offset towards increased risk and a seeming dose response in terms of an increase with increasing magnetic field exposure at low MF levels of 0.2 to $0.4 \mu \mathrm{T}$ [4]-[8]. However, for the general public existing guidelines and regulations allow ELF MF exposures three orders of magnitudes above these values [9] [10]. The limit has even been doubled recently [9] without any idea whether and how the reported dose dependence should be extrapolated to exposures three orders of magnitudes above reported risk onset levels. This dilemma raises concern whether limits provide a sufficient safety level. Unfortunately, after several decades of epidemiological research, more of the same research cannot be expected to clarify the issue even in the future. Consequently, without a new approach risk believers and deniers are expected to further continue their controversy.

It is striking that so far only little use has been made of most of the already existing epidemiologic evidence. On the one hand (fortunately), it has become frequent practice that papers on epidemiological studies include tables with extensive numbers (up to about hundred) of ORs which have been calculated for a variety of different scenarios and exposure metrics. However, so far conclusions have been based only on few selected results.

In the new approach, the synoptic analysis makes use of the entire pool and selected sub-pools of available data rather than restricting to just a few selected results. This allows assessing consistency of data and dependencies of ORs on various parameters by joint evaluation. With this approach, it could already be shown that the reliability of reported ORs critically depends on the associated number of exposed cases [11] [12]. In the RF range, two quite different data pools with seeming controversial results could be identified. However, the synoptic analysis could clarify this discrepancy by showing that with increasing statistical power ORs of the contradictory data pools converge towards the same OR which, even more, turned out to be 0.8 , hence, indicating decreased risk from mobile phone use [12]. In the ELF range, contradictory data pools could not be found. All reported data (except some few outliers) fitted well within one common pattern with ORs converging towards one single final value, in this case towards zero risk $(\mathrm{OR}=1)$. This finding does not support the hypothesis of a causal relationship of childhood leukemia and ELF MF exposure [11].

However, this reassuring result can be challenged by the argument, that by pooling all reported ORs, an increased risk can have been masked by data from exposure scenarios with no risk, hence leaving the issue still open. Therefore, for further clarification, this paper concentrates on additional aspects, in particular on the worrying OR offset and the reported OR dose response. It will be shown that the synoptic approach allows generating convincing evidence and drawing consistent conclusions which can explain the reasons for the disturbing contradictions and controversial conclusions.

\section{Method}

For synoptic analysis, all available risk estimates published from 1979 until 2015 were pooled irrespective their statistical significance. Studies were identified by a literature search in the data bases PUBMED, FEMU, IEEE Xplore and MEDLINE with the keywords "childhood leukemia + magnetic fields + epidemiologic study". All identified studies were included without further selection such as due to their size or exposure metric. In case, ORs were given both unadjusted and adjusted for cofactors, the latter were used. However, for some analyses, ORs had to be accompanied by quantitative information on at least the related number of exposed cases or the quantitative exposure level. For quantitative analysis, the nominal scale of the "wire code" was converted into an ordinal scale by assigning numbers to author's verbally described classes, namely "very low" = 1 , "ordinary low" = 2, "medium" = 3, "ordinary high" = 4 and "very high" = 5. In case OR values were given both unadjusted and adjusted for cofactors, the latter were included. The body of data was investigated with the Microsoft Excel software in particular:

1) at the overall data pool with regard to a dependence of ORs on the number of associated exposed cases $\mathrm{N}_{\exp }$ 
(as surrogate for statistical power) to check the acceptability of the null hypothesis (no MF-induced CL risk);

2) at sub-pools generated for different exposure parameters to check the consistency of results among different exposure metrics and the acceptability of the null hypothesis;

3 ) at sub-pools of different exposure parameters to investigate a potential dose response in terms of a the dependence of ORs on exposure levels;

4) at sub-pools of different exposure parameters related to high and low exposure to investigate the impact of the statistical power $\left(\mathrm{N}_{\exp }\right)$ on a potential dose response.

\section{Results}

Overall, compared to the synoptic analysis of 2014 [11] some more studies could be included. The literature search resulted in 252 hits which were manually selected, ending up with 48 papers on childhood leukemia studies (excluding studies on devices and CL) [13]-[60]. More than 1500 reported OR values could be analyzed. It is important to note that inclusion of additional studies did not change the pattern of the overall data pool as previously presented. Figure 1 shows the pattern of all ORs in dependence on the associated number of exposed cases $\left(\mathrm{N}_{\text {exp }}\right)$ including different exposure metrics and scenarios. It exhibits the already known funnel-shaped pattern with ORs scattered on either side of the zero-risk line $(\mathrm{OR}=1)$. It can be seen that many ORs are based on few or even one case only. Consequently, it is no surprise that the variance of ORs is rather high at small $\mathrm{N}_{\exp }$ and because of random influences extends to either side of the zero-risk line. It is obvious that ORs and conclusions based on only few exposed leukemia cases are not very reliable and hence exhibit a high variance. However, ORs exhibit an offset towards increased risk. Among other arguments this has been interpreted as indicator for increased childhood leukemia risk. However, note that this offset is mainly restricted to small $\mathrm{N}_{\text {exp }}$. In addition, it is important to note that the offset decreases and finally disappears with increasing $\mathrm{N}_{\text {exp }}$. As already shown in the previous analysis [11], the ORs decrease with increasing statistical power $\left(\mathrm{N}_{\exp }\right)$. Moreover, ORs approach the zero-risk line from either side of the zero-risk line. Finally they converge towards zero-risk, and with some variance-remain there with further $\mathrm{N}_{\exp }$ increase.

Interestingly, the same result can be found at sub-pools of different exposure parameters. In the data sub-pools of "wire code" (WC), "distance to MF source" (DMS) and "magnetic field immission" (MFI) with increasing $\mathrm{N}_{\exp }$ ORs consistently show the same pattern, the similar decrease of OR offset, the similar decrease of

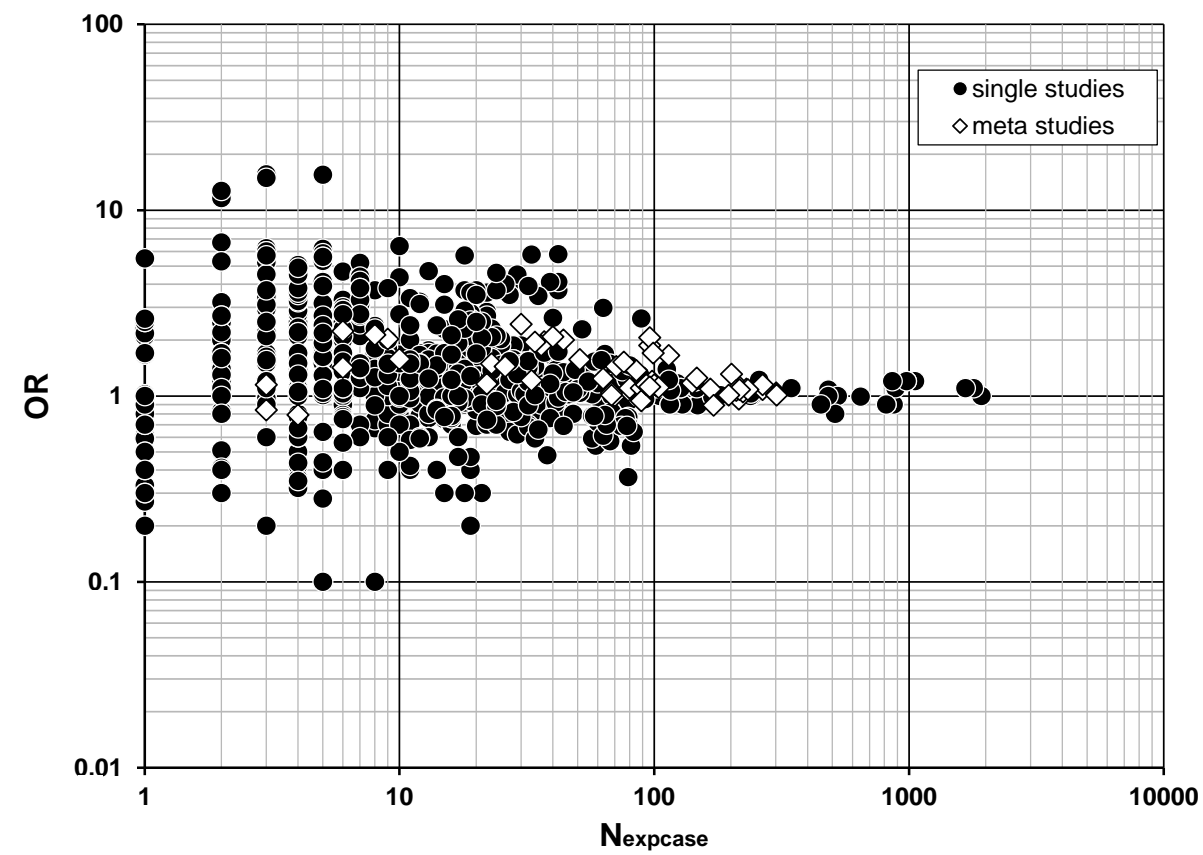

Figure 1. All reported odds ratios (OR) of 42 epidemiological studies on childhood leukemia and ELF magnetic field exposure in dependence on the associated number of exposed cases $\mathrm{N}_{\text {exp }}$. 
ORs and the similar convergence towards zero risk (Figure 2). This is not self-evident since this happens in spite of the quite different assessment strategies and different reliability of the exposure parameters.

The overall data pattern demonstrates that ORs critically depend on $\mathrm{N}_{\exp }$ and decrease with increasing $\mathrm{N}_{\exp }$. However, this finding could be challenged by the argument, existing evidence for increased childhood leikemia risk at higher exposures could be masked by lacking risk at low exposure. To clarify this, a potential dependence of ORs on exposure level was investigated at different exposure parameters. The results at all exposure parameters are presented Figure 3. It shows that ORs increase with increasing exposure level even beyond $0.4 \mu \mathrm{T}$ (note that MF immission increases with decreasing DMS). It is not self-evident that the increase is found at each of the exposure parameters. In the past, such a result had been interpreted as dose response and hence, as evidence for increased CL risk. This premature conclusion has become one of the main reasons for public concern.

However, such a premature conclusion ignores one important aspect, namely, that in Figure 3 all ORs are given the same weight. However, this is not justified. Figure 1 and Figure 2 demonstrated already that the reliability of ORs significantly depends on the associated $\mathrm{N}_{\text {exp }}$. Since highly exposed cases are rare compared to less exposed, it is no surprise that the data analysis showed that $\mathrm{N}_{\text {exp }}$ decreases with exposure (results not shown here, but can be verified by looking at Figures 4-6). This means that the statistical power and hence the reliability of ORs decreases with increasing exposure level. Therefore, the seeming dose-response shown in Figure 3 needs to be interpreted with care. For further clarification, sub-pools were created for low and high exposure levels, respectively. The associated data distributions were analyzed in dependence of $\mathrm{N}_{\exp }$ as a surrogate for statistical power.

Figure 4 shows the results for wire codes. The related data were separated into a sub-pool of low exposure (wiring configurations "very low" and "ordinary low") and a sub-pool of high exposure ("ordinary high" and "very high"), respectively. Wire coding stood at the beginning of epidemiologic investigations and later was substituted by quantitative immission assessment. Therefore, wire code data are less numerous and, hence, the sub-pool patterns less filled (note that there is still an overlap of similar data points, therefore not all available data points can be identified). It is important to note that in spite of fewer data, both sub-pools clearly exhibit the same generic properties as found in the overall data pools (see Figure 1 and Figure 2), namely, ORs scattered around either side of the zero-risk line. In addition, both sub-pools show the tendency of ORs to converge towards zero risk, although less clear because of fewer data points. It can be seen that the range of $\mathrm{N}_{\text {exp }}$ associated with high exposure extends to much smaller numbers and ORs exhibit both larger variance and larger offset compared to the low-exposure sub-pool. That indicates a small-number effect probably due to selection bias. It needs to be noted, that there is no systematic difference between the patterns of high and low exposure which could indicate dose response in terms of a higher CL risk at high exposure. Consequently, with regard to WC data the seeming exposure-response shown in Figure 3 is not supported by Figure 4.

Similar to WC data also from the data of the exposure surrogate "distance from MF source" two sub-pools were generated related to high $(d \leq 50 \mathrm{~m})$ and low exposure $(d>100 \mathrm{~m})$, respectively. Figure 5 shows that in spite of generic similarities both data sub-pools exhibit impressing differences. Again, it can be clearly seen that $\mathrm{N}_{\text {exp }}$ are much smaller at the high-exposure data with a majority of ORs based on less than 10 exposed cases while in the low-exposure sub-pool $\mathrm{N}_{\text {exp }}$ are about 10 fold higher. Consequently, the OR variance is much higher in the high-exposure sub-pool. In addition, there is again an obvious offset of ORs towards increased risk at small $\mathrm{N}_{\text {exp }}$. However, with increasing $\mathrm{N}_{\exp }$ it rapidly decreases, and ORs clearly converge towards zero risk with offset remaining. Interestingly, ORs of the low-exposure sub-pool do not have any offset from the zero-risk line: They are almost equally scattered around either side of the line $\mathrm{OR}=1$. Thus, DMS data are not indicating an increased leukaemia risk. The remaining OR variance at larger $\mathrm{N}_{\exp }$ reflects methodological uncertainties in DMS assessment. It is much lower than at WC and MFI data. The patterns of the DMS sub-pools are in agreement with the overall pooled patterns (Figure 1 and Figure 2) as well as with WC data (Figure 4). The differences between low- and high-exposure sub-pools stem from the different ranges of $\mathrm{N}_{\text {exp }}$. Overall, there is no indication of a dose response and an increased childhood leukaemia risk from DMS data.

From the data related to quantitative MFI assessment (which includes measurements as well as numerical field calculation with quite different assessment strategies) sub-pools were generated for high $(>200 \mu \mathrm{T})$ and low immission $(\leq 100 \mu \mathrm{T})$, respectively. Results are presented in Figure 6 . In the high-exposure sub-pool $\mathrm{N}_{\text {exp }}$ is much smaller with many ORs associated with one or two exposed cases only. The variance of ORs is large and decreases with increasing $\mathrm{N}_{\text {exp }}$. The OR offset decreases with $\mathrm{N}_{\text {exp }}$ and disappears rapidly with increasing $\mathrm{N}_{\text {exp }}$. 

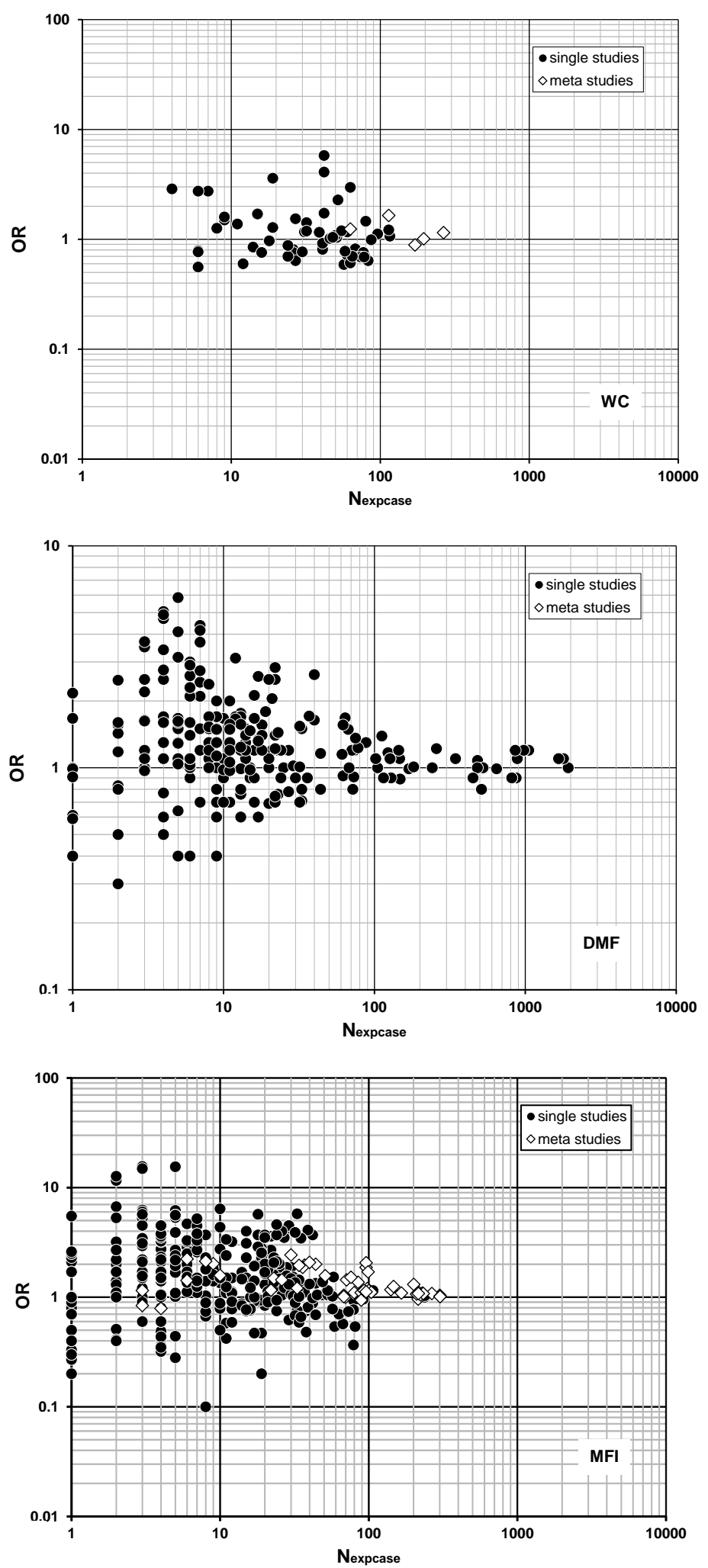

Figure 2. Reported odds ratios (OR) of epidemiological studies on childhood leukemia and ELF magnetic field exposure over the associated number of exposed cases $\mathrm{N}_{\text {exp }}$ for different exposure metrics; wiring code (WC, in ordinal scale, above), distance to MF source (DMF, middle), magnetic field immission (MFI, below). 

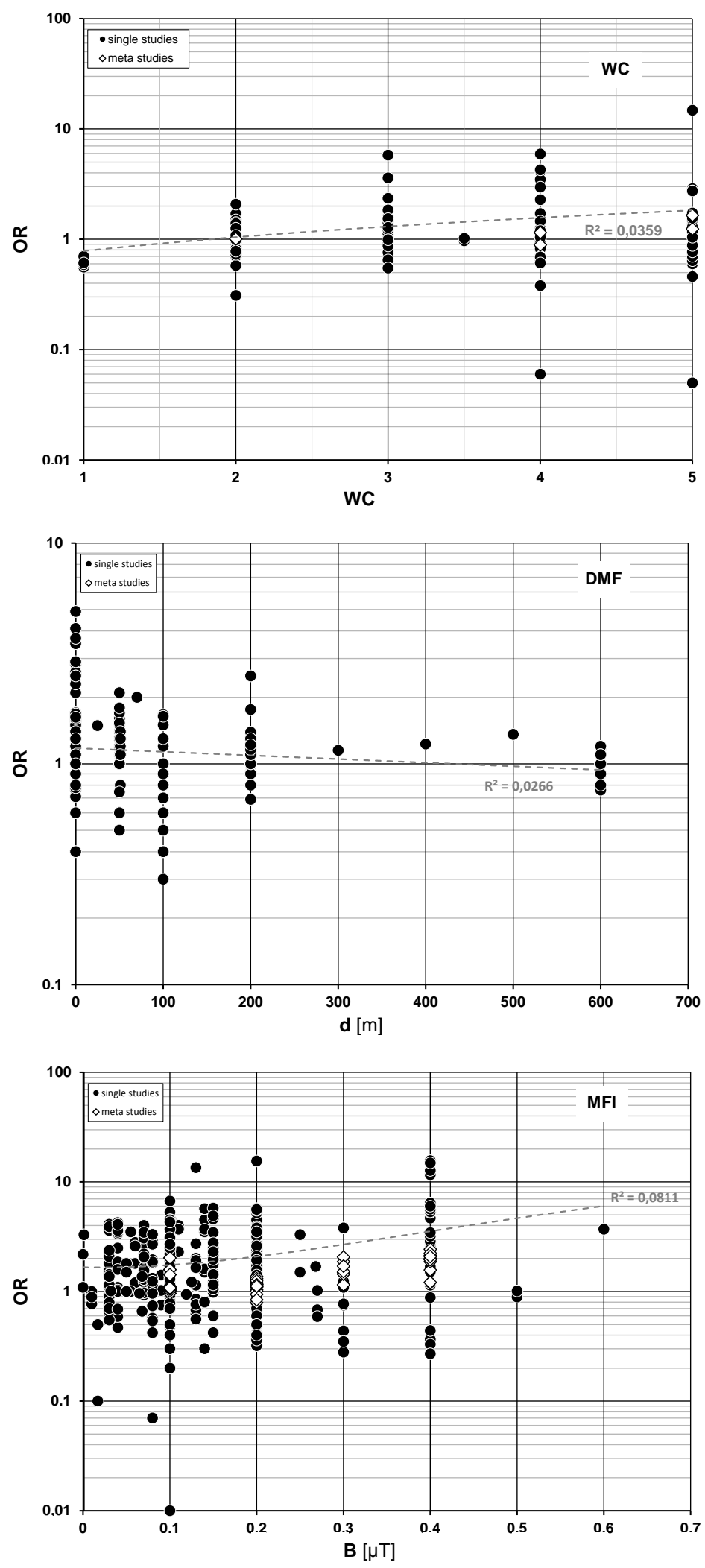

Figure 3. Childhood leukemia risk estimates (OR) over ELF magnetic field exposure level characterized by wiring code WC (in ordinal scale, above), distance to MF source d (DMF, middle), magnetic field immission B (MFI, below). 

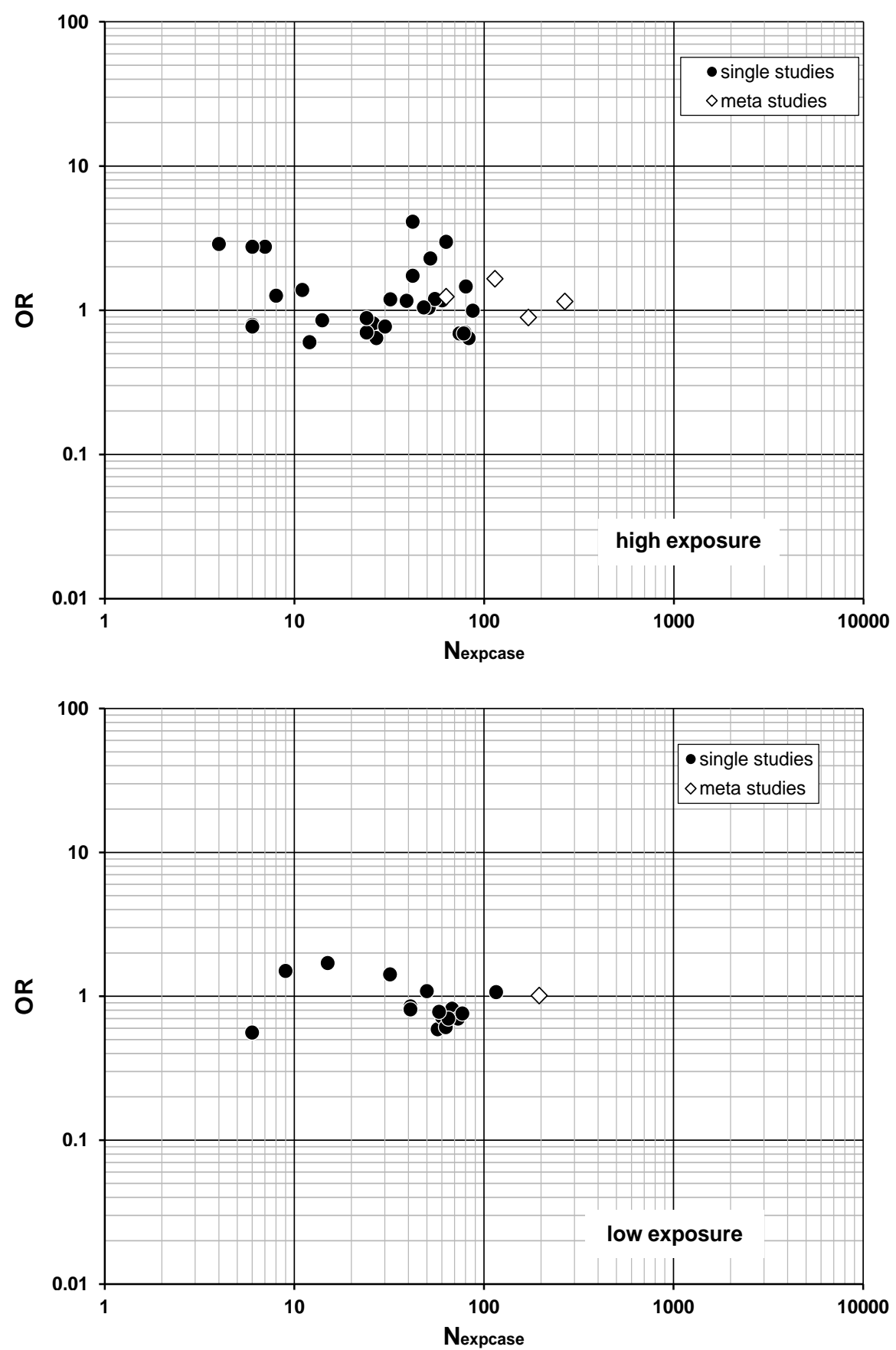

Figure 4. Reported odds ratios (OR) of epidemiological studies on childhood leukemia and ELF magnetic field exposure assessed by wiring codes (WC) over the associated number of exposed cases $\mathrm{N}_{\text {exp }}$ for data sub-pools related to high and low exposure, namely WC "ordinary high" and "high" (above) and "ordinary low” and "low”(below), respectively.

Similar to the other exposure parameters ORs decrease with increasing $\mathrm{N}_{\exp }$ and converge towards the zero-risk line from either side. In the low-exposure sub-pool ORs are distributed around the zero risk line with neither offset nor further convergence. Note that the variance is larger compared to the other exposure parameters. This can be explained by the many different ways magnetic field values were derived. Overall, all generic features of MFI sub-pool patterns are in agreement with those of the other exposure parameters. There is no indication of a dose response and an increased CL risk with increasing MFI level. 

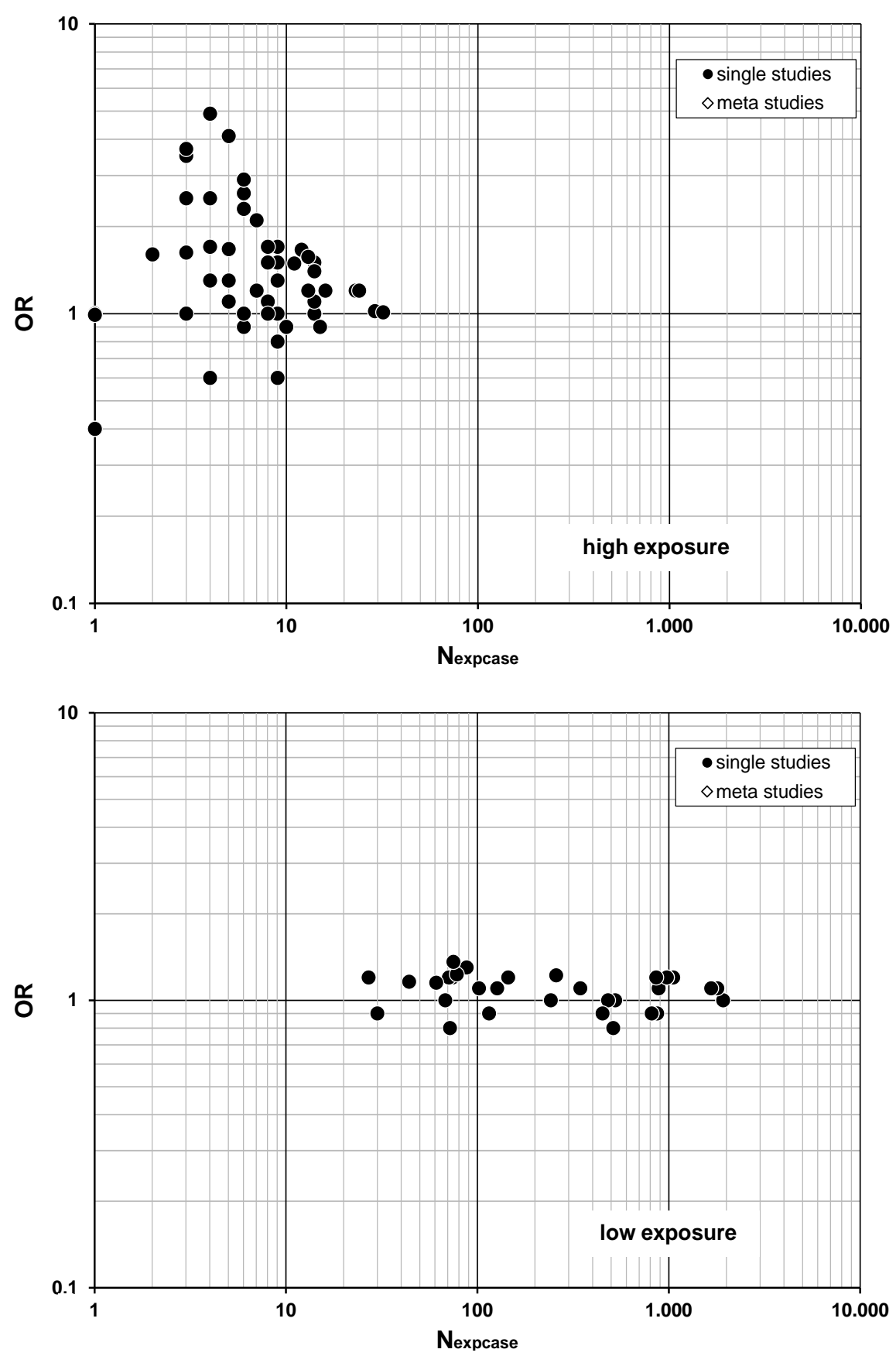

Figure 5. Reported odds ratios (OR) of epidemiological studies on childhood leukemia and ELF magnetic field exposure level assessed by "distance to magnetic field source" $d$ over the associated number of exposed cases $\mathrm{N}_{\text {exp }}$ for data sub-pools related to high and low exposure, namely $d \leq 50 \mathrm{~m}$ (above) and $d>100 \mathrm{~m}$ (below), respectively.

\section{Discussion}

The results show that the synoptic analysis provides additional information by including all available ORs rather than focusing at only one or few ORs selected by whatever consideration. It was decided to accept all available studies instead of rejecting studies based on exclusion criteria. Rejection would make it necessary to justify the dismissal (or acceptance) of studies and may be challenged by one or another stakeholder, by "believers" or "non-believers" of a MF induced health risks. In addition, selection may be prone to bias. This is demonstrated 

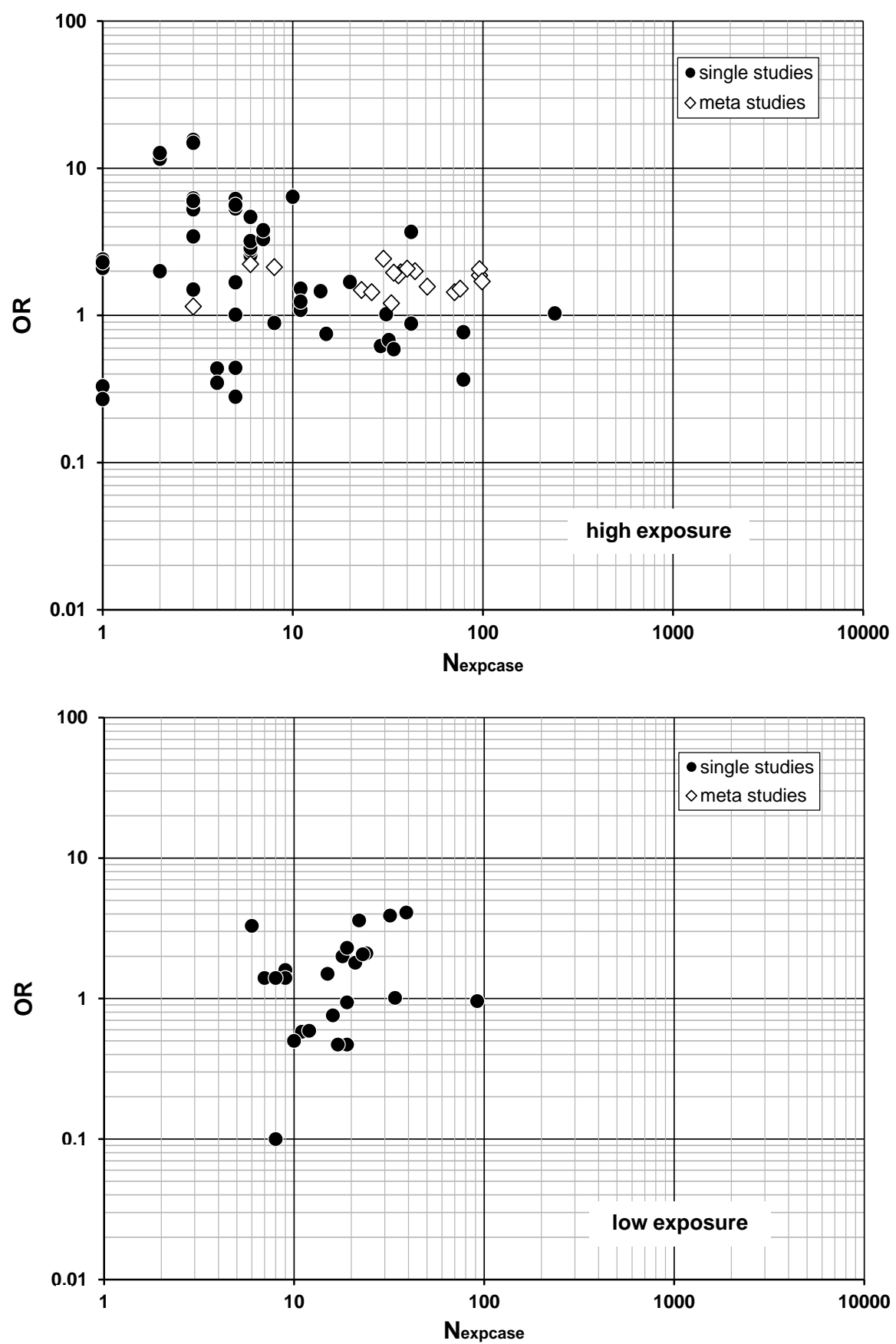

Figure 6. Reported odds ratios (OR) of epidemiological studies on childhood leukemia and power frequency magnetic field exposure assessed by the estimated magnetic field levels (MFI) over the associated number of exposed cases $N_{\exp }$ for data sub-pools related to high and low exposure, namely MFI > $200 \mathrm{nT}$ (above) and MFI $\leq 100 \mathrm{nT}$ (below), respectively.

by the fact that different groups such as ICNIRP and WHO versus Bioinitiative give quite different weight to the same studies. In contrast, not selecting does not require to justify selection criteria. However, this could also be challenged, this time by the argument, included weak studies could degrade the result. However, the advantage of the synoptic approach is to easily allow identifying whether studies fit into the overall body of evidence or suffer from methodical insufficiencies as those identified at mobile phone studies [12]. Likewise, this applies to outliers who are easily identified by their location aside the data pattern (see Figure 1 and Figure 2). It is inter- 
esting to note that the pattern of data from meta-analyses differs strikingly from the general pattern. However, detailed discussion would go beyond the scope of this paper. It can be found elsewhere [61].

It needs to be noted that not all reported data could be included into the synoptic analysis namely those cases where needed OR-associated information such as on $\mathrm{N}_{\exp }$ or exposure level were lacking. Therefore, even more data points could have been considered if published and if more authors would have refrained from restricting reporting on just few selected ORs only. However, the available body of data is already impressively large and stable. The inclusion of some more studies since the first synoptic analysis [11] did not change neither the data pattern nor the derived conclusions (note that due to overlapping ORs the added data points are hardly visible). Consequently, there is little reason to assume that further studies could lead to relevant changes. This is why synoptic analysis of the already available data allows drawing convincing conclusions in particular since some sparse data in sub-pools such as of the wire code are compensated by consistent support from other parameters.

The synoptic analysis allowed clarifying worrying issues and puzzling results. It is important to note that now the reported OR offset towards increased risk can be explained. The offset disappears if $\mathrm{N}_{\text {exp }}$ becomes large enough. This finding is supported by the fact that the same is seen at all exposure parameters irrespective their considerable methodical differences. This provides convincing evidence of a low-number artifact. It is obvious that a case-selection bias in terms of an unjustified selection of an exposed case has a larger impact if only one or few cases are used for OR calculation (note that a similar offset could also be seen at data of other childhood cancer [11]). The existence of a case-selection bias has already been discussed by others [62]-[65]. Therefore, there are convincing indication that the offset towards increased risk is an artifact caused by low-number effects which amplifies existing selection bias. It can no longer be taken as an indicator for an increased risk.

Another worrying issue could also be explained, namely the reported "dose-response". So far, it was puzzling to assume that ORs increased just within limited MF levels. On the one hand studies reported on a proportional OR increase with magnetic immission between $0.2 \mu \mathrm{T}$ and $0.4 \mu \mathrm{T}$. However, on the other hand there was no idea how such a finding —if causal—could be extrapolated to higher exposures, in particular over three orders of magnitudes to the existing exposure limits. It is one merit of the synoptic analysis to be able to convincingly show that the conclusion on a "dose-response" is a consequence of the low-number aitifact. It can be explained by the coincidence of decreasing $\mathrm{N}_{\exp }$ with increasing exposure which, as a consequence, causes a higher variance, and an increased offset of ORs due to the amplified selection bias at smaller $\mathrm{N}_{\text {exp. }}$. It is evident that such a bias does not endlessly increase. It is no surprise that it levels out. This explains why at higher MF levels a further increased leukemia risk could not be found. This is in agreement with the fact that the OR offset diminishes at higher $\mathrm{N}_{\text {exp }}$. It is convincing that the same generic behavior was seen at quite different exposure parameters, namely, the decrease of OR offset with increasing number of cases and decreasing OR values with increasing $\mathrm{N}_{\text {exp }}$. In addition, the reported "dose response" could not be confirmed at sub-pools of different exposure level and exposure metric. In contradiction to the dose-response hypothesis, in the exposure-related sub-pools ORs did not converge towards different endpoints. On contrary, irrespective the exposure metric ORs of high and low exposure sub- pools converged towards the same endpoint, which, in addition, consistently indicated zero risk $(\mathrm{OR}=1)$. This finding does not support the hypothesis of a causal relationship between CL and ELF MF.

The synoptic analysis demonstrated that there is a remaining variance in ORs even if $\mathrm{N}_{\exp }$ is large and the result stable. Moreover, the residual variance was different at different exposure parameters. This reflects methodical uncertainties and is in agreement with the fact that different exposure parameters are based on quite different approaches and metrics. Therefore, they suffer from different causes and amounts of uncertainty. It is interesting to note that the residual variance of ORs is highest at MFI which had been expected to perform better than the surrogates WC and DMS. The reason for this are the highly different assessment strategies associated with MFI levels such as measurement or numerical calculation at different spots within or outside homes, at different points in time (at diagnosis, before diagnosis, at study), instantaneous values or averaged values derived from different time intervals (daytime, nighttime, year) determined in different ways such as spot values, time averages, time arithmetic medians, time geometric means, time-weighted averages with different thresholds etc. The unavoidable residual variance is the reason why conclusions from single selected ORs even if based on high $\mathrm{N}_{\text {exp }}$ still suffer from uncertainty. This demonstrates the need of a synoptic approach.

It is one more argument against a causal relationship of childhood leukemia and magnetic field exposure that over decades of various attempts it was not possible to identify and agree upon a single reliable exposure metric.

The convincing evidence that the reported increase of ORs with MF levels does not indicate a dose-response nor a causal relationship now solves the dilemma of health risk assessment bodies and authorities, in particular 
of WHO who, on the one hand, concluded on a possible childhood leukemia risk from ELF MF exposure already at low environmental MF levels, and on the other hand stayed with exposure limits several orders of magnitude above reported risk onset levels.

The synoptic results allow terminating the long-term debate about a potential childhood leukemia risk from ELF magnetic field exposure with a reassuring message. The synoptic analysis provided convincing evidence that a causal relationship simply does not exist and risk of childhood leukemia is not increased by exposure to ELF magnetic fields. This is in agreement with the fact that in spite of intensive attempts the CL risk hypothesis could not be convincingly supported by an interaction mechanism, nor by in vitro or in vivo results or by explanations of the puzzling situation, that similar health risks could not be found in children nor at other cancer endpoints nor in even much higher exposed adults. The convincing evidence of lacking causality between childhood leukemia and exposure to ELF MF demonstrates that IARC's classification needs revision, the sooner the better.

However, the synoptic analysis of the entire body of available data from epidemiologic studies also leads to an important overarching conclusion, namely, that statistical power e.g. in terms of the number of exposed cases used for calculating ORs must not be neglected. Consequently, in epidemiology (not only on EMF) reported ORs need to be accompanied by associated $\mathrm{N}_{\text {exp }}$. So far, this is already done by many authors but has not yet become general routine.

Another overarching consequence applies to reviews (and reviewers) which compare Ors from several studies. It is no longer justified to give all ORs the same weight. It is also inappropriate to list ORs in a manner which is not at all causally related with ORs such as in alphabetical order (e.g. of the first authors) instead of presenting ORs in dependence of a relevant parameter such as $\mathrm{N}_{\text {exp }}$. Therefore, reviews that did not yet weigh ORs with the associated $\mathrm{N}_{\text {exp }}$ need to be interpreted with care.

\section{Conclusion}

The synoptic analysis is proofed to be an important and powerful tool. It avoids ignoring valuable information and is demonstrating the importance of weighing risk estimates (ORs) with their associated statistical power $\left(\mathrm{N}_{\text {exp }}\right)$. It allows clarifying the worrying offset of ORs towards increased risk and the seeming dose-response as an artifact caused by the small-number effect. It demonstrates that the indication of increased CL risk decreases with increasing statistical power until it diminished. This is consistently shown at the overall pooled data as well as at all investigated sub-pools of different exposure parameters. The results of the synoptic analysis allow terminating the long-term controversy about a potential childhood leukemia risk from ELF magnetic field exposure with a reassuring message. The synoptic analysis provides convincing evidence that a causal relationship does not exist and risk of childhood leukemia is not increased by exposure to magnetic fields. Consequently, IARC's classification of ELF MF as class 2B carcinogen needs revision.

\section{Conflict of Interest}

The author declares no conflict of interest.

\section{References}

[1] Wertheimer, N. and Leeper, N. (1979) Electric Wiring Configurations and Childhood Cancer. American Journal of Epidemiology, 109, 273-284.

[2] IARC (2002) IARC Monographs on the Evaluation of Carcinogenic Risks to Humans. Vol. 80, Non-Ionizing Radiation, Part 1: Static and Extremely Low-Frequency (ELF) Electric and Magnetic Fields, IARC, Lyon.

[3] Grellier, J., Ravazzani, P. and Cardis, E. (2014) Potential Health Impacts of Residential Exposure to Extremely Low Frequency Magnetic Fields in Europe. Environment International, 62, 55-63. http://dx.doi.org/10.1016/j.envint.2013.09.017

[4] WHO (2008) Environmental Health Criteria 238. Extremely Low Frequency Fields. WHO, Geneva.

[5] Ahlbom, A., Day, N., Feychting, M., Roman, E., Skinner, J., Dockerty, J., Linet, M., McBride, M., Michaelis, J., Olsen, J.H., Tynes, T. and Verkasalo, P.K. (2000) A Pooled Analysis of Magnetic Fields and Childhood Leukemia. British Journal of Cancer, 83, 692-698. http://dx.doi.org/10.1054/bjoc.2000.1376

[6] Greenland, S., Sheppard, A.R., Kaune, W.T., Poole, C. and Kelsh, M.A. (2000) A Pooled Analysis of Magnetic Fields, Wire Codes, and Childhood Leukemia. Epidemiology, 11, 624-634.

http://dx.doi.org/10.1097/00001648-200011000-00003 
[7] Kheifets, L., Ahlbom, A., Draper, G., Haghira, J., Lowenthal, R.M., Mezei, G., Oksuzyan, S., Schüz, J., Swanson, J., Tittarelli, A., Vincenti, M. and Wünsch-Filho, V. (2010) Pooled Analysis of Recent Studies on Magnetic Fields and Childhood Leukemia. British Journal of Cancer, 103, 1128-1135. http://dx.doi.org/10.1038/sj.bjc.6605838

[8] Schüz, J. and Ahlbom, A. (2008) Exposure to Electromagnetic Fields and the Risk of Childhood Leukemia: A Review. Radiation Protection Dosimetry, 132, 202-211. http://dx.doi.org/10.1093/rpd/ncn270

[9] ICNIRP (2010) Guidelines for Limiting Exposure to Time-Varying Electric and Magnetic Fields (1 Hz to $100 \mathrm{kHz}$ ). Health Physics, 99, 818-836.

[10] EU (2013) Directive on the Minimum Health and Safety Requirements Regarding Exposure of Workers to the Risks Arising from Physical Agents (Electromagnetic Fields). Official Journal of the European Union, L179, 1-18.

[11] Leitgeb, N. (2014) Childhood Leukemia Not Linked with ELF Magnetic Fields. Journal of Electric and Magnetic Analysis and Applications, 6, 174-183. http://dx.doi.org/10.4236/jemaa.2014.67017

[12] Leitgeb, N. (2014) Synoptic Analysis of Epidemiologic Evidence of Brain Cancer Risks from Mobile Communication. Journal of Electric and Magnetic Analysis and Applications, 6, 413-424. http://dx.doi.org/10.4236/jemaa.2014.614043

[13] Salvan, A., Ranucci, A., Lagorio, S. and Magnani, C. (2015) Childhood Leukemia and 50Hz Magnetic Fields: Findings from the Italian SETIL Case-Control Study. International Journal on Environmental Research and Public Health, 12, 2184-2204. http://dx.doi.org/10.3390/ijerph120202184

[14] Zhao, L.Y., Liu, X.D., Wang, C.P., Yan, K.K., Lin, X.J., Li, S., Bao, H.H. and Liu, X. (2014) Magnetic Fields Exposure and Childhood Leukemia Risk: A Meta-Analysis Based on 11,699 Cases and 13,194 Controls. Leukemia Research, 38, 269-274. http://dx.doi.org/10.1016/j.leukres.2013.12.008

[15] Bunch, K.J., Keegan, T.J., Swanson, J., Vincent, T.J. and Murphy, M.F.G. (2014) Residential Distance at Birth from Overhead High-Voltage Power Lines: Childhood Cancer Risk in Britain 1962-2008. British Journal of Cancer, 110, 1402-1408. http://dx.doi.org/10.1038/bjc.2014.15

[16] Sermage-Faure, C., Demoury, C., Rudant, J., Goujon-Bellec, S., Guvot-Goubin, A., Deschamps, F., Hemon, P. and Clavel, J. (2013) Childhood Leukemia Close to High-Voltage Power Lines-The Geocap Study, 2002-2007. British Journal of Cancer, 109, 1899-1906. http://dx.doi.org/10.1038/bjc.2013.128

[17] Jirik, V., Pekarek, L., Janout, V. and Tomaskova, H. (2012) Association between Childhood Leukemia and Exposure to Power Frequency Magnetic Fields in Middle Europe. Biomedical and Environmental Sciences, 25, 597-601.

[18] Wünsch-Filho, V., Pelissari, D.M., Barbieri, F.E., Sant’Anna, L., Oliviera, C.T., de Mata, J.F., Tone, L.G., Lee, M.L.D.M., de Andréa, M.L.M., Bruniera, P., Epelman, S., Filho, V.O. and Kheifets, L. (2011) Exposure to Magnetic Fields and Childhood Acute Lymphocytic Leukemia in Sao Paolo, Brazil. Cancer Epidemiology, 35, 534-539. http://dx.doi.org/10.1016/j.canep.2011.05.008

[19] Malagoli, C., Fabbi, S., Teggi, S., Calzari, M., Poli, M., Ballotti, E., Notari, B., Bruni, M., Palazzi, G., Paolucci, G. and Vincenti, M. (2010) Risk of Hematological Malignancies Associated with Magnetic Fields Exposure from Power Lines: A Case-Control Study in Two Municipalities of Northern Italy. Environmental Health, 9, 16. http://dx.doi.org/10.1186/1476-069X-9-16

[20] Kroll, M.E., Swanson, J., Vincent, T.J. and Draper, G.J. (2010) Childhood Cancer and Magnetic Fields from HighVoltage Power Lines in England and Wales: A Case-Control Study. British Journal of Cancer, 103, 1122-1127. http://dx.doi.org/10.1038/sj.bjc.6605795

[21] Sohrabi, M.-R., Tarjoman, T., Abadi, A. and Yavari, P. (2010) Living Near Overhead High-Voltage Transmission Power Lines as a Risk Factor for Childhood Acute Lymphoblastic Leukemia: A Case-Control Study. Asian Pacific Journal of Cancer Prevention, 11, 423-427.

[22] Maslanyj, M., Simpson, J., Roman, E. and Schüz, J. (2009) Power Frequency Magnetic Fields and Risk of Childhood Leukemia: Misclassification of Exposure from the Use of the "Distance from Power Line" Exposure Surrogate. Bioelectromagnetics, 30, 183-188. http://dx.doi.org/10.1002/bem.20465

[23] Rahman, H.I.A., Shah, S.A., Alias, H. and Ibrahim, H.M. (2008) A Case-Control Study on the Association between Environmental Factors and the Occurrence of Acute Leukemia among Children in Klang Valley, Malaysia. Asian Pacific Journal of Cancer Prevention, 9, 649-652.

[24] Schüz, J., Svendsen, A.L., LInet, M.S., McBride, M.L., Roman, E., Feychting, M., Kheifets, L., Lightfood, T., Mezel, G., Simpson, J. and Ahlbom, A. (2007) Nighttime Exposure to Electromagnetic Fields and Childhood Leukemia: An Extended Pooled Analysis. American Journal of Epidemiology, 166, 263-269. http://dx.doi.org/10.1093/aje/kwm080

[25] Kabuto, M., Nitta, H., Yamamoto, S., Yamaguchi, N., Akiba, S., Honda, Y., Hagihara, J., Isaka, K., Saito, T., Ojima, T., Nalamura, Y., Mizoue, T., Iti, S., Eboshida, A., Yamazaki, S., Sokejima, S., Kurokawa, Y. and Kubo, O. (2006) Childhood Leukemia and Magnetic Fields in Japan: A Case-Control Study of Childhood Leukemia and Residential Power-Frequency Magnetic Fields in Japan. International Journal of Cancer, 119, 643-650. http://dx.doi.org/10.1002/ijc.21374 
[26] Draper, G., Vincent, T., Kroll, M.E. and Swanson, J. (2005) Childhood Cancer in Relation to Distance from High Voltage Power Lines in England and Wales: A Case-Control Study. British Medical Journal, 330, 1290-1293. http://dx.doi.org/10.1136/bmj.330.7503.1290

[27] Mizoue, T., Onoe, Y., Moritake, H., Okamura, J., Sokejima, S. and Nitta, H. (2004) Residential Proximity to HighVoltage Power Lines and Risk of Childhood Hematological Malignancies. Journal of Epidemiology, 14, 118-123. http://dx.doi.org/10.2188/jea.14.118

[28] Söderberg, K.C., Naumburg, E., Ander, G., Cnattingius, S., Ekborn, A. and Feychting, M. (2002) Childhood Leukemia and Magnetic Fields in Infant Incubators. Epidemiology, 13, 45-49. http://dx.doi.org/10.1097/00001648-200201000-00008

[29] Schüz, J., Grigat, J.-P., Brinkmann, K. and Michaelis, J. (2001) Residential Magnetic Fields as a Risk Factor for Childhood Acute Leukemia: Results from a German Population-Based Case-Control Study. International Journal of Cancer, 91, 728-735. http://dx.doi.org/10.1002/1097-0215(200002)9999:9999<::AID-IJC1097>3.0.CO;2-D

[30] Bianchi, N., Crosignani, P., Rovelli, A., Titterelli, A., Carnelli, C.A., Rossitto, F., Vanelli, U., Porro, E. and Berrino, F. (2000) Overhead Electricity Power Lines and Childhood Leukemia: A Registry-Based Case-Control Study. Tumori, 86, 195-198.

[31] Skinner, J., Maslanyi, M.P., Mee, T.J., Allen, S.G., Simpson, J., Roman, E. and Day, N.E. (2000) Childhood Cancer and Residential Proximity to Power Lines. British Journal of Cancer, 83, 1573-1580. http://dx.doi.org/10.1054/bjoc.2000.1550

[32] Auvinen, A., Line, M.S., Hatch, E.E., Kleinerman, R.A., Robinson, L.L., Kaune, W.T., Misakian, M., Niwa, S., Wacholder, S. and Tarone, R.E. (2000) Extremely-Low Frequency Magnetic Fields and Childhood Acute Lymphoblastic Leukemia: An Exploratory Analysis of Alternative Exposure Metrics. American Journal of Epidemiology, 152, $20-31$. http://dx.doi.org/10.1093/aje/152.1.20

[33] Kleinerman, R.A., Kaune, W.T., Hatch, E., Wacholder, S., Linet, M.S., Robinson, L., Niwa, S. and Tarone, R. (2000) Are Children Living near High Voltage Power Lines at Increased Risk of Acute Lymphoblastic Leukemia? American Journal of Epidemiology, 151, 512-515. http://dx.doi.org/10.1093/oxfordjournals.aje.a010237

[34] McBride, M.L., Gallagher, R.P., Thériault, G., Armstrong, B.G., Tamaro, S., Spinellil, J.J., Deadman, J.E., Finchman, S., Robson, D. and Choi, W. (1999) Power-Frequency Electric and Magnetic Fields and Risk of Childhood Leukemia in Children. American Journal of Epidemiology, 149, 831-842. http://dx.doi.org/10.1093/oxfordjournals.aje.a009899

[35] Green, L.M., Miller, A.B., Villeneuve, P.J., Agnew, D.A., Greenberg, M.L., Li, J. and Donelly, K.E. (1999) A CaseControl Study of Childhood Leukemia in Southern Ontario, Canada, and Exposure to Magnetic Fields in Residences. International Journal of Cancer, 82, 161-170. http://dx.doi.org/10.1002/(SICI)1097-0215(19990719)82:2<161::AID-IJC2>3.0.CO;2-X

[36] Cheng, K.K., Day, N., Cartwright, R., Craft, A., Birch, J.M., Eden, O.B., McKinney, P.A., Petro, J., Beral, V., Roman, E., Elwood, P., Alexander, F.E., Chilvers, C.E.D., Doll, R., Taylor, C.M., Greaves, M., Goodhead, D., Fry, F.A. and Adams, G. (1999) Exposure to Power-Frequency Magnetic Fields and the Risk of Childhood Cancer. The Lancet, 354, 1925-1931. http://dx.doi.org/10.1016/S0140-6736(99)10074-6

[37] Green, L.M., Miller, A.B., Agnew, D.A., Greenberg, M.L., Li, J., Villeneuve, P.J. and Tibshirian, R. (1999) Childhood Leukemia and Personal Monitoring of Residential Exposures to Electric and Magnetic Fields in Ontario. Cancer Causes and Control, 10, 233-243. http://dx.doi.org/10.1023/A:1008919408855

[38] Dockerty, J.D., Elwood, J.M., Skegg, D.C.G. and Herbison, G.P. (1998) Electromagnetic Field Exposures and Childhood Cancers in New Zealand. Cancer Causes and Control, 9, 299-309. http://dx.doi.org/10.1023/A:1008825220759

[39] Li, C.-Y., Lee, W.-C. and Lin, R.S. (1998) Risk of Leukemia in Children Living near High-Voltage Transmission Lines. Journal of Occupational and Environmental Medicine, 40, 144-147. http://dx.doi.org/10.1097/00043764-199802000-00010

[40] Linet, M.S., Hatch, E., Kleinerman, R.A., Robinson, L.L., Kaune, W.T., Friedman, D.R., Secverson, R.K., Haines, C.M., Hartsock, C.T., Niwa, S., Wacholder, S. and Tarone, R. (1997) Residential Exposure to Magnetic Fields and Acute Lymphoblastic Leukemia in Children. New England Journal of Medicine, 337, 1-8. http://dx.doi.org/10.1056/NEJM199707033370101

[41] Michaelis, J., Schüz, J., Meinert, R., Menger, M., Grigart, J.-P., Kaatsch, P., Kaletsch, U., Miesner, A., Stamm, A., Brinkmann, K. and Kärner, H. (1997) Childhood Leukemia and Electromagnetic Fields: Results of a Population-Based Case-Control Study in Germany. Cancer Causes and Control, 8, 167-174. http://dx.doi.org/10.1023/A:1018464012055

[42] Petridou, E., Trichopoulos, D., Kravaritis, A., Pourtsidis, A., Dessypris, N., Skalkidis, Y., Kogevinas, M., Kalmanti, V., Koliouskas, H., Panagiotou, J.P., Piperopoulou, F., Tzortzatou, F. and Kalapothaki, V. (1997) Electric Power Lines and Childhood Leukemia: A Study from Greece. International Journal of Cancer, 73, 345-348. http://dx.doi.org/10.1002/(SICI)1097-0215(19971104)73:3<345::AID-IJC7>3.0.CO;2-\#

[43] Tynes, T. and Haldorsen, T. (1997) Electromagnetic Fields and Cancer in Children Residing near Norwegian High- 
Voltage Power Lines. American Journal of Epidemiology, 145, 219-226.

http://dx.doi.org/10.1093/oxfordjournals.aje.a009094

[44] Coghill, R.W., Steward, J. and Philips, A. (1996) Extra Low Frequency Electric and Magnetic Fields in the Bedplace of Children Diagnosed with Leukemia: A Case-Control Study. European Journal of Cancer Prevention, 5, 153-158. http://dx.doi.org/10.1097/00008469-199606000-00002

[45] Lin, R.S., Lee, W.-C. and Li, C.-Y. (1996) Risk of Childhood Leukemia in Households near High Power Lines. Medical and Biological Engineering and Computing, 34, 131-132.

[46] Preston-Martin, S., Navidi, W., Thomas, D., Lee, P.-J., Bowman, J. and Pododa, J. (1996) Los Angeles Study of Residential Magnetic Fields and Childhood Brain Tumors. American Journal of Epidemiology, 143, 105-119. http://dx.doi.org/10.1093/oxfordjournals.aje.a008717

[47] Wertheimer, N., Savitz, D.A. and Leeper, E. (1995) Childhood Cancer in Relation to Indicators of Magnetic Fields from Ground Current Sources. Bioelectromagnetics, 16, 86-96. http://dx.doi.org/10.1002/bem.2250160204

[48] Lin, R.S. and Lee, W.C. (1994) Risk of Childhood Leukemia in Areas Passed by High Power Lines. Review on Environmenal Health, 10, 97-103. http://dx.doi.org/10.1515/reveh.1994.10.2.97

[49] Fajardo-Guitérrez, A., Garduno-Espinosa, J., Yamamoto-Kimura, L., Hernández-Hernández, D.M., Gómez-Delgado, A. and Martínez-Garcia, M.D.C. (1993) Residencia cercana a fuentes electrical de alta tension y su asociación con Leukemia en ninos. Boletín médico del Hospital Infantil de México, 50, 32-38.

[50] Feychting, M. and Ahlbom, A. (1993) Magnetic Fields and Cancer in Children Living near Swedish High-Voltage Power Lines. American Journal of Epidemiology, 138, 467-481.

[51] Olsen, J.H., Nielsen, A. and Schulgen, G. (1993) Residence near High Voltage Facilities and Risk of Cancer in Children. British Journal of Cancer, 307, 891-895. http://dx.doi.org/10.1136/bmj.307.6909.891

[52] Verkasalo, P.K., Pukkala, E., Hongisto, M.Y., Valjus, J.E., Järvinen, P.J., Heikkilä, K.V. and Koskenvou, M. (1993) Risk of Cancer in Finnish Children Living Close to Power Lines. British Medical Journal, 307, 895-899. http://dx.doi.org/10.1136/bmj.307.6909.895

[53] Feychting, M. and Ahlbom, A. (1992) Magnetic Fields and Cancer in People Residing near Swedish High Voltage Power Lines. Institutet Miljömedicin Rapport 6/92, Karolinska Institutet, Stockholm.

[54] London, S.J., Thomas, D.C., Bowman, J.D., Soberl, E., Cheng, T.-C. and Peters, J.M. (1991) Exposure to Residential Electric and Magnetic Fields and Risk of Childhood Leukemia. American Journal of Epidemiology, 134, 923-937.

[55] Myers, A., Clayden, A.D., Cartwright, R.A. and Cartwright, S.C. (1990) Childhood Cancer and Overhead Powerlines: A Case-Control Study. British Journal of Cancer, 62, 1008-1014. http://dx.doi.org/10.1038/bjc.1990.428

[56] Savitz, D.A., John, E.M. and Kleckner, R.C. (1990) Magnetic Field Exposure from Electric Appliances and Childhood Cancer. American Journal of Epidemiology, 131, 763-773.

[57] Coleman, M.P., Bell, C.M.J., Taylor, H.L. and Primic-Zakeli, M. (1989) Leukemia and Residence near Electric Transmission Equipment: A Case-Control Study. British Journal of Cancer, 60, 793-798. http://dx.doi.org/10.1038/bjc.1989.362

[58] Savitz, D.A., Wachtel, H., Barnes, F.A., John, E.M. and Tvrdik, J. (1988) Case-Control Study of Childhood Cancer and Exposure to 60-Hz Magnetic Fields. American Journal of Epidemiology, 128, 21-38.

[59] Tomenius, L. (1986) 50-Hz Electromagnetic Environment and the Incidence of Childhood Tumors in Stockholm County. Bioelectromagnetics, 7, 191-207. http://dx.doi.org/10.1002/bem.2250070209

[60] Fulton, J.P., Cobb, S., Preble, L., Leone, L. and Forman, E. (1980) Electrical Wiring Configurations and Childhood Leukemia in Rhode Island. American Journal of Epidemiology, 111, 292-296.

[61] Elwood, J.M. (2006) Childhood Leukaemia and Residential Magnetic Fields: Are Pooled Analyses More Valid than the Original Studies? Bioelectromagnetics, 27, 112-118. http://dx.doi.org/10.1002/bem.20181

[62] Slusky, D.A., Does, M., Metayer, C., Mezei, G., Selvin, S. and Buffler, P.A. (2014) Potential Role of Selection Bias in the Association between Childhood Leukemia and Residential Magnetic Field Exposure. A Population-Based Assessment. Cancer Epidemiology, 38, 307-313. http://dx.doi.org/10.1016/j.canep.2014.02.010

[63] Maslanyi, M., Slimpson, J. and Schüz, J. (2009) Power Frequency Magnetic Fields and Risk of Childhood Leukemia: Misclassification of Exposure from the Use of "Distance from Power Line” Exposure Surrogate. Bioelectromagnetics, 30, 183-188. http://dx.doi.org/10.1002/bem.20465

[64] Mezei, G. and Kheifets, L. (2006) Selection Bias and Its Implications for Case-Control Studies: A Case Study of Magnetic Field Exposure and Childhood Leukemia. International Journal of Epidemiology, 15, 397-406.

[65] Greenland, S., Schwartzbaum, J.A. and Finkle, W.D. (2000) Problems Due to Small Samples and Sparse Data in Conditional Logistic Regression Analysis. American Journal of Epidemiology, 151, 531-539.

http://dx.doi.org/10.1093/oxfordjournals.aje.a010240 